\title{
Autoimmune Comorbidities Are Associated with Brain Injury in Multiple Sclerosis
}

\author{
(D) Rivadinov, (DB. Raj, (D) M. Ramanathan, (D). Teter, (D). Durfee, (D) M.G. Dwyer, (D) N. Bergsland, (D). Kolb, (DD. Hojnacki,
}

(D) R.H. Benedict, and (DB. Weinstock-Guttman

\begin{abstract}
BACKGROUND AND PURPOSE: The effect of comorbidities on disease severity in MS has not been extensively characterized. We determined the association of comorbidities with MR imaging disease severity outcomes in MS.
\end{abstract}

MATERIALS AND METHODS: Demographic and clinical history of 9 autoimmune comorbidities confirmed by retrospective chart review and quantitative MR imaging data were obtained in 815 patients with MS. The patients were categorized on the basis of the presence/ absence of total and specific comorbidities. We analyzed the MR imaging findings, adjusting for key covariates and correcting for multiple comparisons.

RESULTS: Two hundred forty-one (29.6\%) study subjects presented with comorbidities. Thyroid disease had the highest frequency $(n=$ $97,11.9 \%)$, followed by asthma ( $n=41,5 \%)$, type 2 diabetes mellitus $(n=40,4.9 \%)$, psoriasis $(n=33,4 \%)$, and rheumatoid arthritis $(n=22$, 2.7\%). Patients with MS with comorbidities showed decreased whole-brain and cortical volumes $(P<.001)$, gray matter volume and magnetization transfer ratio of normal-appearing brain tissue $(P<.01)$, and magnetization transfer ratio of gray matter $(P<.05)$. Psoriasis, thyroid disease, and type 2 diabetes mellitus comorbidities were associated with decreased whole-brain, cortical, and gray matter volumes $(P<.05)$. Psoriasis was associated with a decreased magnetization transfer ratio of normal-appearing brain tissue $(P<.05)$, while type 2 diabetes mellitus was associated with increased mean diffusivity $(P<.01)$.

CONCLUSIONS: The presence of comorbidities in patients with MS is associated with brain injury on MR imaging. Psoriasis, thyroid disease, and type 2 diabetes mellitus comorbidities were associated with more severe nonconventional MR imaging outcomes.

ABBREVIATIONS: EDSS = Expanded Disability Status Scale; $L V=$ lesion volume; $M T R=$ magnetization transfer ratio; $M D=$ mean diffusivity; NABT = normalappearing brain tissue; $\mathrm{PD}=$ proton density

$\mathbf{M}^{\mathrm{s}}$ $\mathrm{S}$ is a chronic immune-mediated disorder that affects the CNS and is characterized by specific clinical and MR imaging findings. ${ }^{1}$ Studies have suggested genetic, environmental, and infectious agents as interacting factors influencing the risk for development of MS. ${ }^{2,3}$

Received October 2, 2015; accepted after revision November 25.

From the, Department of Neurology (R.Z., B.R., J.D., M.G.D., N.B.), Buffalo Neuroimaging Analysis Center, and Department of Neurology (B.T., C.K., D.H., R.H.B., B.W.-G.), Jacobs MS Center, University at Buffalo, State University of New York, Buffalo, New York; MR Imaging Clinical Translational Research Center (R.Z.) and Department of Pharmaceutical Sciences (M.R.), School of Medicine and Biomedical Sciences, State University of New York, Buffalo, New York; and Magnetic Resonance Laboratory (N.B.), IRCCS Don Gnocchi Foundation, Milan, Italy.

Robert Zivadinov, Brian Raj, Bianca Weinstock-Guttman and Murali Ramanathan substantially contributed to the concept and design of the study. Robert Zivadinov drafted the article, while all authors revised it critically for important intellectual content. Robert Zivadinov and Brian Raj performed statistical analysis. All authors had access to the data.

This study was funded by internal resources of the Buffalo Neuroimaging Analysis Center and Department of Neurology, University of Buffalo. In addition, we received support from the National Multiple Sclerosis Society (RG4836A5, RR2007A2) and Department of Defense (MS090122).
Epidemiologic evidence from the North American Research Committee on Multiple Sclerosis, the large registry containing patient self-reported data, suggests an increased risk for disability progression in individuals with MS who have additional comorbidities. ${ }^{4}$ An increased prevalence of autoimmune- and nonimmune-mediated comorbidities was reported in patients with MS compared with the general population. ${ }^{5-14}$ Examples of the most frequent comorbidities or secondary disorders that co-occur with MS include thyroid disease, rheumatoid arthritis, psoriasis, cardiovascular disorders, depression and anxiety, diabetes mellitus, chronic lung disease, and irritable bowel syndrome, among others. ${ }^{4-6,8-10,14,15}$ The pathogenesis of these associations with MS is unclear at this time but may be linked to a genetic predisposi-

Please address correspondence to Robert Zivadinov, MD, PhD, Buffalo Neuroimaging Analysis Center, Department of Neurology, University at Buffalo, School of Medicine and Biomedical Sciences, 100 High St, Buffalo, NY 14203; e-mail: rzivadinov@bnac.net

- Indicates open access to non-subscribers at www.ajnr.org

http://dx.doi.org/10.3174/ajnr.A4681 
tion, ${ }^{5,16,17}$ the presence of a chronic inflammatory condition, ${ }^{10}$ environmental factors, ${ }^{18}$ and the use of disease-modifying therapy. ${ }^{19}$

It has been postulated that CD4 + T-cells of the Th1 phenotype, CD8 + T-cells, and B-cells play a key role in focal and diffuse destruction of the CNS in patients with MS. ${ }^{20}$ The immune deviation of CD $4+$ T-cells into Th1 and Th2 phenotypes has been the subject of many immunologic and epidemiologic studies in MS. ${ }^{21,22}$ In particular, it has been reported that Th1 responses associated with autoimmunity may be attenuated by a Th 2 shift. ${ }^{13}$ Several studies reported a positive association of comorbidities in patients with MS when explored from the Th1/Th2 point of view. ${ }^{13,22,23}$ However, some other studies suggested that these associations were related more to a demographic selection bias than a true sharing of immunologic and pathologic processes. ${ }^{14}$

Conventional MR imaging examines visible focal inflammatory changes within the CNS. However, it does not capture the true extent of diffuse GM and WM pathology that is mostly undetected in patients with MS and responsible for long-term development of disability progression. ${ }^{24}$ On the other hand, nonconventional MR imaging techniques are more sensitive biomarkers for measuring these nonfocal pathologic processes associated with tissue damage in the GM and WM and that are better associated with disease severity. ${ }^{24}$ Some of these techniques include measures of brain atrophy, magnetization transfer imaging, DWI and DTI, MR spectroscopy, and functional MR imaging.

It has been shown that patients with MS with $\geq 1$ cardiovascular risk factor have increased lesion burden and more advanced brain atrophy on MR imaging. ${ }^{25,26}$ However, it is not clear whether the presence of other comorbidities may also influence the severity of conventional and nonconventional MR imaging measures in patients with MS. Therefore, in this large-cohort MS study, we aimed to investigate the impact of autoimmune comorbidities on the severity of conventional and nonconventional MR imaging outcomes in patients with MS.

\section{MATERIALS AND METHODS Study Population}

The study was approved by the institutional review board, and all subjects provided written informed consent.

Clinical, demographic, MR imaging, and comorbidity data were prospectively collected during the New York State Multiple Sclerosis Consortium annual follow-up visit at the Buffalo site. The inclusion criteria for this study were the following: MR imaging examination performed at the time of the clinical visit $( \pm 30$ days), 18-70 years of age, Expanded Disability Status Scale (EDSS) score of $0-8.5$, diagnosis of MS according to the McDonald criteria, ${ }^{27}$ and collection of comorbidity information. Exclusion criteria consisted of relapse and steroid treatment in the 30 days preceding study entry and insufficient quality of the MR image for quantitative analysis. Clinical data included the presence, type, and duration of disease-modifying treatment; MS clinical subtype; and disease duration and disability as measured by the EDSS score. Information on autoimmune comorbidities was collected from a questionnaire, ${ }^{28}$ which was completed at the time of the clinical visit. We included information on the following autoimmune comorbidities: asthma, Crohn disease, type 1 and 2 diabetes mellitus, myasthenia gravis, psoriasis, rheumatoid arthritis, systemic lupus erythematosus, and thyroid disease. The self-report comorbidity information obtained from the questionnaire was cross-examined against the medical record chart review to determine the accuracy of the reported data. Only self-reported comorbidities confirmed by the retrospective chart review were used in the present analyses.

\section{MR Imaging Acquisition}

Patients underwent brain MR imaging by using a 1.5T Signa $4 \mathrm{x} / \mathrm{Lx}$ scanner (GE Healthcare, Milwaukee, Wisconsin) with an 8-channel head and neck coil. Dual-echo proton density (PD)/T2WI, DWI, 3D spoiled gradient-recalled T1WI, spin-echo T1WI with and without gadolinium contrast, FLAIR, PD, and PD with magnetization transfer pulse images were obtained. All images were acquired axially. The PD/T2 sequence was acquired with the following parameters: TE, 30/90 ms; TR, $3000 \mathrm{~ms}$; NEX, 1; echotrain length, 14; FOV, $24 \times 18 \mathrm{~cm}^{2}$; matrix, $192 \times 256$; 5-mm section thickness with a total of 28 sections; no gap. The 3D T1WI sequence was acquired with the following parameters: FOV, $24 \times$ $18 \mathrm{~cm}^{2}$; matrix, $192 \times 256$; 2.5 -mm section thickness; 70 sections; no gap; TE, 7 ms; TR, 24 ms; NEX, 1; flip angle, $30^{\circ}$. Axial FLAIR was acquired with the following parameters: FOV, $24 \times 24 \mathrm{~cm}^{2}$; matrix, $192 \times 256$; 28 sections; 5 -mm section thickness; no gap; TE, $128 \mathrm{~ms}$; TI, $2000 \mathrm{~ms}$; TR, 8002 ms; echo-train length, 22; NEX, 1. PD was acquired with the following parameters: FOV, $24 \times 24$ $\mathrm{cm}^{2}$; matrix, $192 \times 256$; 28 sections; 5 -mm section thickness; no gap; TE, 12 ms; TR, 1400 ms; NEX 1. A similar PD with magnetization transfer contrast had a 1200-Hz off-resonance pulse. Spinecho T1WI was acquired with the following parameters: FOV, $24 \times 18 \mathrm{~cm}^{2}$; matrix, $192 \times 256$; 28 sections; 5 -mm section thickness; no gap; TE, 9 ms; TR, 600 ms; NEX, 2, while the gadoliniumenhanced spin-echo T1WI sequence was obtained after injection of a single-dose intravenous bolus ( $0.1 \mathrm{mmol} / \mathrm{Kg}$ of Gd-DTPA) 5 minutes after administration of the contrast agent. Echo-planar imaging was used to obtain T2WI $\left(b=0 \mathrm{~s} / \mathrm{mm}^{2}\right)$ and DWI $\left(b=1000 \mathrm{~s} / \mathrm{mm}^{2}\right)$ with the following parameters: FOV, $36 \times 27$ $\mathrm{cm}^{2}$; matrix, $128 \times 128$; 46 sections; 3 -mm section thickness; no gap.

\section{MR Imaging Analysis}

The image analysis was blinded to patient clinical and sex characteristics. The patients were assessed for a number of conventional and nonconventional MR imaging measures.

Lesion Measures. The T1-, T2-, and gadolinium-lesion volumes (LVs) were calculated by using a highly reproducible, semiautomated local contour-thresholding technique for lesion segmentation. ${ }^{29}$

Brain Volume Measures. For brain extraction and tissue segmentation, we used the SIENAX 2.6 cross-sectional brain atrophy analysis tool (http://fsl.fmrib.ox.ac.uk/fsl/fslwiki/SIENA). ${ }^{30}$ Global and tissue-specific normalized volumes were quantified for the whole brain, GM (normalized gray matter volume), WM (normalized white matter volume), cortex (normalized cortical volume), and lateral ventricle volume (normalized lateral ventricle volume). ${ }^{31}$ Images were preprocessed by using an in-house- 
Table 1: Demographic and clinical characteristics of patients with MS with and without comorbidities ${ }^{a}$

\begin{tabular}{|c|c|c|c|c|}
\hline & $\begin{array}{l}\text { Total Patients with } \\
\text { MS }(N=815)\end{array}$ & $\begin{array}{l}\text { Patients with MS with } \\
\text { Comorbidities }(n=241)\end{array}$ & $\begin{array}{l}\text { Patients with MS without } \\
\text { Comorbidities }(n=574)\end{array}$ & $P$ Value ${ }^{\text {b }}$ \\
\hline Females (No.) (\%) & $626(76.8)$ & $201(83.4)$ & $425(74.0)$ & .300 \\
\hline Age (yr) (mean) (SD) & $45.7(10.3)$ & $46.3(10.4)$ & $45(10.2)$ & .082 \\
\hline Disease duration (yr) (mean) (SD) & $13.1(9.4)$ & $13.3(10)$ & $12.8(8.8)$ & .452 \\
\hline EDSS (median) (IQR) & $2.5(1.5-6.0)$ & $2.5(1.5-5.5)$ & $2.5(2.0-6.0)$ & .732 \\
\hline \multicolumn{5}{|l|}{ MS subtype (No.) (\%) } \\
\hline $\mathrm{RR}$ & $554(67.9)$ & $157(65.1)$ & $397(69.2)$ & .120 \\
\hline SP & $227(27.9)$ & $77(32.0)$ & $150(26.1)$ & \\
\hline PP & $34(4.2)$ & $7(2.9)$ & $27(4.7)$ & \\
\hline DMT use (No.) (\%) & $598(73.4)$ & $175(72.6)$ & $423(73.7)$ & .900 \\
\hline DMT months (mean) (SD) & $48.9(35.2)$ & $48.8(35.2)$ & $49(39.2)$ & .942 \\
\hline
\end{tabular}

Note:-RR indicates relapsing-remitting; SP, secondary-progressive; PP, primary-progressive; DMT, disease-modifying therapy; IQR, interquartile range.

${ }^{a}$ Demographic and clinical characteristics were tested using the $\chi^{2}$, Student $t$, and Mann-Whitney rank sum tests.

${ }^{\mathrm{b}} P$ values refer to analyses between patients with MS with and without comorbidities.

developed lesion in-painting technique to minimize the effects of T1 hypointensities on tissue segmentation.

Magnetization Transfer Measures. FLAIR, 3D spoiled gradientecho T1WI, and PD + magnetization transfer images were coregistered to the PD image. The FLAIR and T1WI lesion masks were used to nullify overt lesions, and the remaining PD was algebraically combined with the coregistered PD + magnetization transfer (MT) images with the following equation: Percentage Magnetization Transfer Ratio $(\mathrm{MTR})=[\mathrm{PD}-(\mathrm{PD}+\mathrm{MT})] / \mathrm{PD} \times 100$ to generate whole-brain (in case the lesions were not nullified), normal-appearing brain tissue (NABT), normal-appearing gray matter, normal-appearing white matter, or T2-LV maps. The mean MTR of the final image was calculated for each tissue class.

Diffusivity Measures. The whole-brain mean diffusivity (MD) was computed from the T2 and DWIs, which were combined to create an MD map by performing the following calculation on each voxel:

$$
\bar{D}=(-b / 3) \ln (D W / T 2)
$$

where $D W$ represents the average diffusion signal intensity and $T 2$ represents the T2-weighted signal intensity without the diffusion weighting.

\section{Statistical Analysis}

Statistical analysis was performed by using the Statistical Package for the Social Sciences, Version 21.0 (IBM, Armonk, New York).

The comorbidity status of patients with MS was classified on the basis of the presence/absence of comorbidities. The comorbidity status variable (presence or absence) was created for total and specific comorbidities. Demographic and clinical characteristic differences between subjects with and without the presence of comorbidities were tested by using the $\chi^{2}$, Student $t$, or MannWhitney rank sum test.

To decrease the number of MR imaging variables and statistical tests used in the study, we predetermined primary and secondary MR imaging outcomes for both conventional and nonconventional MR imaging measures. T2-LV, T1-LV, and gadolinium-LV were chosen as primary conventional MR imaging measures because their increase represents accumulation of lesion burden in patients with MS, and normalized brain volume and MTR-NABT were selected as nonconventional MR imaging measures because a normalized brain volume decrease represents an overall loss of brain tissue and an MTR-NABT decrease is a more specific indicator of severity of demyelination. ${ }^{24}$ Secondary MR imaging outcomes were used for further characterization of tissue damage and included the following: 1) tissue-specific brain atrophy measures: normalized gray matter volume, normalized white matter volume, normalized cortical volume, and normalized lateral ventricle volume; 2) MTR measures: normal-appearing gray matter, normal-appearing white matter, and T2-LV; and 3) diffusivity measures: whole-brain MD. MR imaging analyses between patients with MS with and without comorbidities and between patients with MS with specific comorbidities and those without any comorbidities were performed by using ANCOVA, adjusted for age, sex, MS subtype, disability status, and the use and duration of disease-modifying treatment. Given the colinearity between age and disease duration, the latter was not used as a covariate.

The Benjamini-Hochberg correction was used to control the false discovery rate for the primary and secondary MR imaging outcome comparisons between patients with MS with and without comorbidities and between patients with MS with specific comorbidities and those without any comorbidities. Differences in secondary MR imaging outcomes were explored only if significant differences were shown among the primary MR imaging outcomes. False discovery rate-corrected $P$ values $<.05$ were considered significant. $^{32}$

\section{RESULTS}

\section{Demographic and Clinical Characteristics}

The demographic and clinical characteristics of the total cohort of subjects with MS $(N=815)$ and those with $(n=241)$ and without $(n=574)$ comorbidities are summarized in Table 1 . Of the 815 subjects in the study, $598(73.4 \%)$ were on disease-modifying treatment for a mean of 48.9 months: 88 on glatiramer acetate, 445 on interferon- $\beta, 31$ on methotrexate, 25 on intravenous immunoglobulin, 5 on cyclophosphamide, and 4 on azathioprine.

Patients with MS with comorbidities showed a trend toward older age $(P=.082)$. Comorbidities were present in $241(29.6 \%)$ study subjects, and 199 of those $(82.6 \%)$ had 1 , whereas 42 (17.4\%) had $\geq 2$ comorbidities.

The demographic and clinical characteristics of patients with MS with specific comorbidities are shown in Table 2. Among specific comorbidities, thyroid disease showed the highest frequency $(n=97,11.9 \%)$, followed by asthma $(n=41,5 \%)$, type 2 
Table 2: Demographic and clinical characteristics of patients with MS with comorbidities, according to their specific comorbidity type

\begin{tabular}{|c|c|c|c|c|c|c|c|c|c|}
\hline \multirow[b]{2}{*}{ Disease } & \multirow{2}{*}{$\begin{array}{l}\text { Females } \\
\text { (No.) (\%) }\end{array}$} & \multirow{2}{*}{$\begin{array}{c}\text { Age (yr) } \\
\text { (Mean) (SD) }\end{array}$} & \multirow{2}{*}{$\begin{array}{c}\text { DD (yr) } \\
\text { (Mean) (SD) }\end{array}$} & \multirow{2}{*}{$\begin{array}{c}\text { EDSS } \\
\text { (Median) (IQR) }\end{array}$} & \multicolumn{3}{|c|}{ MS Subtype (No.) (\%) } & \multirow{2}{*}{$\begin{array}{l}\text { DMT Use } \\
\text { (No.) (\%) }\end{array}$} & \multirow{2}{*}{$\begin{array}{l}\text { DMT Months } \\
\text { (Mean) (SD) }\end{array}$} \\
\hline & & & & & $\mathbf{R R}$ & SP & PP & & \\
\hline Asthma $(n=41)$ & $38(92.7)$ & $45.2(8.8)$ & $12.4(10.0)$ & $2.5(1.5-5.0)$ & $32(78)$ & $7(17.1)$ & $2(4.9)$ & $32(78.0)$ & $51.7(40.7)$ \\
\hline Crohn disease $(n=1)$ & $1(100)$ & 53 & 16 & 3.0 & $0(0)$ & $1(100)$ & $0(0)$ & $1(100)$ & 60 \\
\hline Diabetes mellitus type $1(n=3)$ & $2(66.6)$ & $36.3(4.7)$ & $6.7(4.2)$ & $2.3(1.5-2.5)$ & $2(66.7)$ & $1(33.3)$ & $0(0)$ & $0(0.0)$ & $0(0)$ \\
\hline Diabetes mellitus type $2(n=40)$ & $28(70.0)$ & $49.3(8.7)$ & $14.5(9$ & $5.5(2.0-5.0)$ & $23(57.5)$ & $16(40)$ & $1(2.5)$ & $29(72.5)$ & $50.9(4$ \\
\hline Myasthenia gravis $(n=1)$ & $1(100)$ & 47 & 12 & 6.5 & $0(0)$ & $1(100)$ & $0(0)$ & $1(100)$ & 24 \\
\hline Psoriasis ( $n=33$ ) & $23(69.7)$ & $50.4(9.1)$ & $15.9(10)$ & $3.0(2.0-5.5)$ & $21(63.6)$ & $11(33.3)$ & $1(3.1)$ & $24(72.7)$ & $63.7(34.2)$ \\
\hline Rheumatoid arthritis ( $n=22$ ) & $17(77.3)$ & $51.8(9.1)$ & $16.4(11.8)$ & $3.0(1.5-5.5)$ & $13(59.1)$ & $8(36.4)$ & $1(4.5)$ & $17(77.2)$ & $58.4(31.4)$ \\
\hline $\operatorname{SLE}(n=3)$ & $2(66.6)$ & $50(3)$ & $15.7(1.5)$ & $4.0(4.0-5.0)$ & $0(0)$ & $3(100)$ & $0(0)$ & $3(100)$ & $50.3(24.6)$ \\
\hline Thyroid disease $(n=97)$ & $89(91.8)$ & $46.6(10.6)$ & $14.6(11.1)$ & $2.5(1.5-5.5)$ & $66(68.0)$ & $29(29.9)$ & $2(2.1)$ & 68 (70.1) & $46.5(35.2)$ \\
\hline
\end{tabular}

Note:-SLE indicates systemic lupus erythematosus; DD, disease duration; RR, relapsing-remitting; SP, secondary-progressive; PP, primary-progressive; DMT, disease-modifying therapy; $\mathrm{IQR}$, interquartile range.

Table 3: Primary and secondary MRI outcomes in patients with MS with and without comorbidities $^{2}$

\begin{tabular}{lccc}
\hline & $\begin{array}{c}\text { Patients with MS with } \\
\text { Comorbidities }(\boldsymbol{n}=\mathbf{2 4 1})\end{array}$ & $\begin{array}{c}\text { Patients with MS without } \\
\text { Comorbidities }(\boldsymbol{n}=\mathbf{5 7 4})\end{array}$ & $\begin{array}{c}\boldsymbol{P} \text { Value } \\
\text { Primary MRI outcomes }\end{array}$ \\
T2-LV & $15.7(15.5)$ & $15.3(18.2)$ & .943 \\
T1-LV & $2.8(4.7)$ & $2.6(4.7)$ & .955 \\
Gd-LV & $0.08(0.3)$ & $0.1(0.4)$ & .992 \\
NBV & $1451.1(97.3)$ & $1481(86.4)$ & $<.001^{\mathrm{b}}$ \\
MTR-NABT & $34.1(5.1)$ & $35.3(5)$ & $.01^{\mathrm{b}}$ \\
Secondary MRI outcomes & & & $.01^{\mathrm{b}}$ \\
NGMV & $722.8(86.9)$ & $747.9(81.5)$ & .311 \\
NWMV & $728.3(86.7)$ & $732.6(64)$ & $<.001^{\mathrm{b}}$ \\
NCV & $537.1(67.3)$ & $557.6(62.8)$ & .528 \\
NLVV & $47.5(20.6)$ & $45.3(20.5)$ & $.045^{\mathrm{b}}$ \\
MTR-NAGM & $31.1(5.5)$ & $32.3(5.1)$ & .105 \\
MTR-NAWM & $37.1(5.3)$ & $38.1(4.9)$ & .650 \\
MTR-T2-LV & $32.3(4.8)$ & $32.8(5.1)$ & .136 \\
MD X 103 & $1.26(0.29)$ & $1.22(0.22)$ &
\end{tabular}

Note:-Gd indicates gadolinium; NWMV, normalized white matter volume; NLVV, normalized lateral ventricle volume; NAGM, normal-appearing gray matter; NBV, normalized brain volume; NGMV, normalized gray matter volume; NCV, normalized cortical volume; NAWM, normal appearing-white matter.

a The data are expressed as mean and SD. Volumes are expressed in milliliters. MTR values are expressed as percentage units. MD is expressed as $\mathrm{mm}^{2} / \mathrm{s}$. Analysis of covariance, adjusted for age, sex, MS subtype, disability status, and use and duration of disease-modifying treatment, was used to explore the difference between patients with MS with and without comorbidities. The Benjamini-Hochberg correction was used to minimize the false discovery rate.

${ }^{\mathrm{b}}$ Corrected $P$ value $<.05$ was significant.

diabetes mellitus $(n=40,4.9 \%)$, psoriasis $(n=33,4 \%)$, and rheumatoid arthritis $(n=22,2.7 \%)$.

\section{Comorbidities and MR Imaging Outcomes}

Because there were only a few subjects with systemic lupus erythematosus $(n=3)$, type 1 diabetes mellitus $(n=3)$, Crohn disease $(n=1)$, and myasthenia gravis $(n=1)$, they were excluded from MR imaging analyses.

Table 3 shows primary and secondary MR imaging outcome differences in patients with MS with and without the presence of comorbidities. Patients with MS with comorbidities showed significantly decreased normalized brain volume and normalized cortical volume (both, $P<.001$ ), normalized gray matter volume and MTR-NABT $(P<.01)$, and MTR-normal-appearing gray matter $(P<.05)$.

Table 4 shows primary and secondary MR imaging outcome differences in patients with MS with specific comorbidities, compared with those without any at all. Patients with MS having psoriasis had significantly decreased normalized brain volume $(P<$ .001), normalized gray matter volume and normalized cortical volume (both, $P<.01$ ), and normalized white matter volume and
MTR-NABT (both, $P<.05$ ). Patients with MS with type 2 diabetes mellitus had significantly decreased normalized cortical volume $(P<.01)$ and normalized brain volume and normalized gray matter volume (both, $P<.05$ ). Patients with MS with thyroid disease had significantly decreased normalized brain volume, normalized gray matter volume, and normalized cortical volume (all, $P<05)$. Patients with MS presenting with rheumatoid arthritis and asthma showed no significant differences on primary MR imaging outcomes; therefore, analysis of secondary MR imaging outcomes was not conducted.

\section{DISCUSSION}

This study investigated the association of autoimmune comorbidities and conventional and nonconventional MR imaging outcomes in patients with MS. Our main finding was that the presence of comorbidities in patients with MS was associated with more severe MR imaging outcomes of neurodegeneration and demyelination. The tissue injury of patients with MS with comorbidities was localized to the GM and particularly to the cortex. Psoriasis, thyroid disease, and type 2 diabetes mellitus comorbidities were associated with more severe MR imaging outcomes.

In general, patients with comorbidities compared with those without had more severe brain damage as evidenced by a number of nonconventional MR imaging measures, including brain atrophy, magnetization transfer imaging, and diffusivity. The findings were significant for psoriasis, type 2 diabetes mellitus, and thyroid disease, though a low occurrence of Crohn disease, type 1 diabetes mellitus, myasthenia gravis, and systemic lupus erythematosus prevented us from exploring the impact of these comorbidities on the MR imaging outcomes. The more severe MR imaging findings in patients with MS having psoriasis is of particular interest, considering that medications beneficial for the treatment of this disease are also effective for treatment of patients with MS. ${ }^{33}$

In addition, we found that patients with MS with type 2 diabetes mellitus showed more severe nonconventional MR imaging 


\begin{tabular}{|c|c|c|c|c|c|c|}
\hline & $\begin{array}{l}\text { Patients with } \\
\text { MS without } \\
\text { Comorbidities } \\
\text { (n= 574) }\end{array}$ & $\begin{array}{l}\text { Patients with } \\
\text { MS with } \\
\text { Asthma } \\
\text { (n=41) }\end{array}$ & $\begin{array}{l}\text { Patients with } \\
\text { MS with Diabetes } \\
\text { Mellitus Type } 2 \\
\text { ( } n=40)\end{array}$ & $\begin{array}{l}\text { Patients with } \\
\text { MS with } \\
\text { Psoriasis } \\
\text { (n=33) }\end{array}$ & $\begin{array}{l}\text { Patients with } \\
\text { MS with } \\
\text { Rheumatoid } \\
\text { Arthritis } \\
\text { (n=22) }\end{array}$ & $\begin{array}{l}\text { Patients with } \\
\text { MS with } \\
\text { Thyroid Disease } \\
\text { ( } n=97)\end{array}$ \\
\hline \multicolumn{7}{|c|}{ Primary MRI outcomes } \\
\hline T2-LV & $15.3(18.2)$ & $12.9(14.2)$ & $19.3(17)$ & $17.2(18.1)$ & $17.1(19.1)$ & $12.9(14.2)$ \\
\hline TI-LV & $2.6(4.7)$ & $2.2(2.7)$ & $2.9(3.5)$ & $3.5(5.2)$ & $3.4(5.9)$ & $2.2(4)$ \\
\hline Gd-LV & $0.1(0.4)$ & $0.08(0.1)$ & $0.1(0.05)$ & $0.04(0.1)$ & $0.1(0.2)$ & $0.08(0.2)$ \\
\hline NBV & $1481(86.4)$ & $1490.6(90.5)$ & $1434.4(89)^{b^{\prime}}$ & $1394.3(105)^{c}$ & $1461.2(91.9)$ & $1454.3(87.3)^{b}$ \\
\hline MTR-NABT & $35.3(5)$ & $36.4(3.7)$ & $35.1(4.5)$ & $33.1(4.7)^{b}$ & $33(4.6)$ & $33.8(5.7)$ \\
\hline \multicolumn{7}{|c|}{ Secondary MRI outcomes } \\
\hline NGMV & 747.9 (81.5) & NA & $708.2(58.9)^{b}$ & $694.4(89)^{\mathrm{d}}$ & NA & $722.9(68.5)^{b}$ \\
\hline NWMV & $732.6(64)$ & NA & $726.3(58.9)$ & $699.8(84)^{\mathrm{b}}$ & NA & $731.3(52.9)$ \\
\hline $\mathrm{NCV}$ & $557.6(62.8)$ & NA & $522.8\left((53.7)^{d}\right.$ & $516.2(91)^{d}$ & NA & $537.9(52.7)^{b}$ \\
\hline NLVV & $45.3(20.5)$ & NA & $52.5(21.5)$ & $50.7(20.8)$ & NA & $45.5(21.3)$ \\
\hline MTR-NAGM & $32.3(5.1)$ & NA & $32(4.3)$ & $30.1(4.7)$ & NA & $30.8(6.2)$ \\
\hline MTR-NAWM & $38.1(4.9)$ & NA & $38.2(4.3)$ & $36.2(5.6)$ & NA & $36.7(5.9)$ \\
\hline MTR-T2-LV & $32.8(5.1)$ & NA & $32.9(4.6)$ & $32.1(4.4)$ & NA & $32.7(5.2)$ \\
\hline$M D \times 10^{3}$ & $1.22(0.22)$ & NA & $1.32(0.37)^{d}$ & $1.25(0.13)$ & NA & $1.23(0.31)$ \\
\hline
\end{tabular}

Note:-NA indicates not available; NBV, normalized brain volume; Gd, gadolinium; NGMV, normalized gray matter volume; NWMV, normalized white matter volume; NCV, normalized cortical volume; NLVV, normalized lateral ventricle volume.

${ }^{a}$ The data are expressed as mean and SD. Volumes are expressed in milliliters. MTR values are expressed as percentage units. MD is expressed as mm²/s. Because there were only a few subjects with systemic lupus erythematosus $(n=3)$, type 1 diabetes mellitus $(n=3)$, Crohn disease $(n=1)$, and myasthenia gravis $(n=1)$, they were excluded from MRI analyses. Because no significant MRI primary outcome differences in patients with MS with asthma and rheumatoid arthritis, compared with patients with MS without any comorbidities, were found, no comparison of secondary MRI outcomes was performed for these comorbidities (NA). Analysis of covariance, adjusted for age, sex, MS subtype, disability status, and use and duration of disease-modifying treatment, was used to explore the difference between patients with MS with specific comorbidities compared with patients with MS without any comorbidities. The Benjamini-Hochberg correction was used to minimize the false discovery rate, and corrected $P$ values $<.05$ were considered significant.

${ }^{\mathrm{b}} P<.05$ shows significant differences of specific comorbidities compared with patients with MS without any comorbidities.

${ }^{c} P<.001$.

${ }^{\mathrm{d}} p<.01$.

outcomes compared with those without. In particular, patients with MS with type 2 diabetes mellitus showed more advanced whole-brain and cortical atrophy. While we observed that patients with MS having asthma had less severe damage on nonconventional MR imaging outcomes compared with those without, these differences did not reach significance after correction for multiple comparisons. Previous clinical studies suggested that having asthma may provide a potential benefit to MS. ${ }^{13,22,23}$

MS is thought to be associated with Th1-mediated autoimmunity, along with diseases such as type 1 diabetes mellitus, rheumatoid arthritis, and psoriasis, ${ }^{22,23}$ though it is evident that MS is not an exclusively Th1 disease, given that humoral immunity is an important contributor to its pathogenesis. ${ }^{1}$ Th2-mediated immunity is involved in the pathogenesis of atopic diseases, such as asthma, eczema, and some allergies. ${ }^{22,34}$ Whether autoimmunity and atopy reflect cytokine polarization and thus are mutually protective in patients with MS is unknown at this time. ${ }^{21-23}$ For example, previous studies showed that ulcerative colitis is positively associated with $\mathrm{MS}^{23}$ while asthma may have positive $22,23,34$ or negative ${ }^{13}$ associations, which could be also related to medications. ${ }^{35}$ Presence of Th1-immune-mediated comorbidities in patients with MS (psoriasis, thyroid disease, and rheumatoid arthritis) may reflect a common underlying pathobiology resulting in increased disease severity, while Th2-immune-mediated comorbidity in patients with MS (asthma) may contribute to shifting of a Th-1- to Th2-immune-mediated response.

The presence of autoimmune comorbidities among patients with MS is in agreement with previously published literature and supports the concept of a link between these disorders and MS. ${ }^{5}$
Marrie et $\mathrm{al}^{5}$ recently reported, in a meta-analysis study, summary rates of $6.4 \%$ for thyroid disease, $7.7 \%$ for psoriasis, and ranges of $0.3 \%-3.64 \%$ for rheumatoid arthritis among patients with MS. In the present study, $11.9 \%$ of patients with MS had thyroid disease, $4 \%$ had psoriasis, and $2.7 \%$ had rheumatoid arthritis. The increased rate of autoimmune thyroid disease in patients with MS with respect to a control population could be influenced by the higher frequencies of major histocompatibility antigens, such as HLA-DRB $1{ }^{\star} 15$ and HLA-DRB ${ }^{\star} 17,{ }^{36}$ or by MS treatment. ${ }^{19}$

While the presence of comorbidities was associated with more severe MR imaging outcomes in the present study, there were no clinical differences between patients with MS with and without comorbidities. Therefore, a better understanding of the genetic and/or epigenetic influences causing these differences can help in identifying patients with MS at risk of more aggressive disease. A temporal disassociation between the detection of more severe damage on MR imaging and its immediate translation to clinical disease severity has been reported previously. ${ }^{24,37-40}$ Different levels of functional reserve and plasticity mechanisms that may compensate for the damage are the most plausible explanations for this phenomenon. ${ }^{39,40}$ When these compensatory mechanisms are exhausted, patients with MS enter a progressive clinical stage more rapidly. ${ }^{24,37}$ Future longitudinal studies should determine whether the presence of autoimmune comorbidities is a contributing factor to an increased risk for clinical and radiologic progression in MS.

Limitations of our study include self-reporting of comorbidities, which was limited to the data-collection instrument. Although the retrospective chart review confirmed the presence of 
self-reported comorbidities and potentially increased the accuracy of the collected data, it was unable to determine the onset time of these autoimmune comorbidities in most of the examined cases. Therefore, we did not include the relative disease duration of these comorbidities as a covariate in our analyses, which limited our analyses to explore only the effect of comorbidity presence/absence on the MR imaging outcomes. Furthermore, we did not define thyroid disease subtypes by laboratory data. There was no case-control group included in the study, which limits interpretation of the comorbidity frequency data; however, our aim was to explore the associations of comorbidities with MR imaging disease severity. The study design was cross-sectional; therefore, the relationship of the comorbidities to MR imaging outcomes should be interpreted with caution.

\section{CONCLUSIONS}

The presence of comorbidities in MS is associated with more severe brain injury on MR imaging. This effect may not be visualized by using lesion burden MR imaging measures.

\section{ACKNOWLEDGMENTS}

We acknowledge Jesper Hagemeier for critical reviewing of the manuscript.

Disclosures: Robert Zivadinov—UNRELATED: Consultancy: Genzyme, EMD Serono, Novartis, IMS Health; Grants/Grants Pending: Genzyme, * EMD Serono, ${ }^{\text {Novartis, * }}$ IMS Health, ${ }^{*}$ Biogen, Teva Pharmaceuticals, ${ }^{*}$ Claret Medical, ${ }^{*}$ InteKrin Therapeutics*; Payment for Lectures (including service on Speakers Bureaus): Genzyme, EMD Serono; OTHER: Robert Zivadinov received personal compensation from Biogen Idec, Teva Pharmaceuticals, EMD Serono, Novartis, Claret Medical, and Genzyme for speaking and consultant fees. He received financial support for research activities from Biogen Idec, Teva Pharmaceuticals, EMD Serono, Novartis, Claret Medical, and Genzyme. He serves on the editorial boards of J Alzheimers Dis, BMC Med, BMC Neurol, Vein and Lymphatics, and Clinical CNS Drugs. He is Treasurer of the International Society for Neurovascular Disease. Murali Ramanathan-UNRELATED: Royalties: self-published textbook; OTHER: Murali Ramanathan received research funding or consulting fees from EMD Serono, Biogen Idec, Pfizer, the National Multiple Sclerosis Society, the Department of Defense, the Jog for the Jake Foundation, the National Institutes of Health, and the National Science Foundation. He received compensation for serving as an Editor from the American Association of Pharmaceutical Scientists. Barbara Teter—UNRELATED: Grants/Grants Pending: EMD Serono,* Biogen Idec, ${ }^{*}$ Novartis, ${ }^{*}$ Genzyme, ${ }^{*}$ Genentech, Teva Pharmaceuticals, ${ }^{*}$ Comments: observational research study grants. Michael G. Dwyer-UNRELATED: Consultancy: EMD Serono, Claret Medical, Comments: Dr Dwyer has served on a scientific advisory board for EMD Serono and provided consulting services to Claret Medical; Grants/Grants Pending: Novartis, ${ }^{\star}$ Comments: investigator-initiated research grant support; OTHER: Michael G. Dwyer has received consultant fees from Claret Medical and EMD Serono. Channa Kolb_UNRELATED: Consultancy: Advisory Board for Teva Pharmaceuticals and Biogen; Payment for Lectures (including service on Speakers Bureaus): speaker's honoraria from Novartis, Teva Pharmaceuticals, Acorda Therapeutics, EMD Serono, and Biogen-Idec. David Hojnacki-UNRELATED: Consultancy: Teva Pharmaceuticals, Biogen, Genzyme, EMD Serono; Payment for Lectures (including service on Speakers Bureaus): Teva Pharmaceuticals, Biogen, Genzyme, EMD Serono; OTHER: David Hojnacki has received speaker's honoraria and consultant fees from Biogen Idec, Teva Pharmaceutical, EMD Serono, Pfizer, and Novartis. Ralph $\mathrm{H}$. Benedict-UNRELATED: Consultancy: Biogen, Genzyme, Genentech, Novartis, Adamas Pharmaceuticals; Grants/Grants Pending: National MS Society, Biogen, Acorda Therapeutics, Novartis, Genzyme, Mallinckrodt; Royalties: Psychological Assessment Resources; OTHER: Ralph Benedict has acted as a consultant or scientific advisory board member for Bayer, Biogen Idec, Actelion Pharmaceuticals, and Novartis. He receives royalties from Psychological Assessment Resources. He has received financial support for research activities from Shire Pharmaceuticals, Accorda Therapeutics, and Biogen Idec. Bianca Weinstock-Guttman-UNRELATED: Board Membership: Novartis; Consultancy: Biogen Idec, Teva Neuroscience, EMD Serono, Novartis, Genzyme, Sanofi, Genentech; Grants/Grants Pending: Biogen Idec, * Teva Neuroscience, ${ }^{\star}$ EMD Serono, ${ }^{*}$ Novartis, ${ }^{*}$ Genzyme, ${ }^{\star}$ Sanofi*; Payment for Lectures (including service on Speakers Bureaus): Biogen Idec, Teva Neuroscience, EMD Serono, Novartis, Genzyme, Sanofi; OTHER: Bianca Weinstock-Guttman received honoraria as a speaker and as a consultant for Biogen Idec, Teva Pharmaceuticals, EMD Serono, Genzyme\&Sanofi, Novartis, and Acorda Therapeutics. Dr Weinstock-Guttman received research funds from Biogen Idec, Teva Pharmaceuticals, EMD Serono, Genzyme\&Sanofi, Novartis, Acorda Therapeutics. *Money paid to the institution.

\section{REFERENCES}

1. Frohman EM, Racke MK, Raine CS. Multiple sclerosis: the plaque and its pathogenesis. N Engl J Med 2006;354:942-55 CrossRef Medline

2. Ascherio A, Munger K. Multiple sclerosis. In: Nelson LM, Tanner CM, Van Den Eeden SK, et al, eds. Neuroepidemiology: From Principles to Practice. New York: Oxford University Press; 2004:188-222

3. Ramagopalan SV, Dobson R, Meier UC, et al. Multiple sclerosis: risk factors, prodromes, and potential causal pathways. Lancet Neurol 2010;9:727-39 CrossRef Medline

4. Marrie R, Rudick R, Horwitz R, et al. Vascular comorbidity is associated with more rapid disability progression in multiple sclerosis. Neurology 2010;74:1041-47 CrossRef Medline

5. Marrie RA, Reider N, Cohen J, et al. A systematic review of the incidence and prevalence of autoimmune disease in multiple sclerosis. Mult Scler 2015;21:282-93 CrossRef Medline

6. Marrie RA, Reider N, Cohen J, et al. A systematic review of the incidence and prevalence of cardiac, cerebrovascular, and peripheral vascular disease in multiple sclerosis. Mult Scler 2015;21:318-31 CrossRef Medline

7. Marrie RA, Reider N, Cohen J, et al. A systematic review of the incidence and prevalence of sleep disorders and seizure disorders in multiple sclerosis. Mult Scler 2015;2:342-49 CrossRef Medline

8. Marrie RA, Reider N, Stuve $\mathrm{O}$, et al. The incidence and prevalence of comorbid gastrointestinal, musculoskeletal, ocular, pulmonary, and renal disorders in multiple sclerosis: a systematic review. Mult Scler 2015;21:332-41 CrossRef Medline

9. Marrie RA, Reider N, Cohen J, et al. The incidence and prevalence of psychiatric disorders in multiple sclerosis: a systematic review. Mult Scler 2015;21:305-17 CrossRef Medline

10. Marrie RA, Yu BN, Leung S, et al; CIHR Team in Epidemiology and Impact of Comorbidity on Multiple Sclerosis. Rising prevalence of vascular comorbidities in multiple sclerosis: validation of administrative definitions for diabetes, hypertension, and hyperlipidemia. Mult Scler 2012;18:1310-19 CrossRef Medline

11. Marrosu MG, Cocco E, Lai M, et al. Patients with multiple sclerosis and risk of type 1 diabetes mellitus in Sardinia, Italy: a cohort study. Lancet 2002;359:1461-65 CrossRef Medline

12. Tettey P, Simpson S Jr, Taylor BV, et al. Vascular comorbidities in the onset and progression of multiple sclerosis. J Neurol Sci 2014; 347:23-33 CrossRef Medline

13. Tremlett HL, Evans J, Wiles CM, et al. Asthma and multiple sclerosis: an inverse association in a case-control general practice population. QJM 2002;95:753-56 CrossRef Medline

14. Ramagopalan SV, Dyment DA, Herrera BM, et al. Clustering of autoimmune disease in families at high risk for multiple sclerosis? Lancet Neurol 2007;6:206-07; author reply 207 Medline

15. Marrie RA. Psychiatric comorbidity in multiple sclerosis: it's not the genes. Mult Scler 2014;20:1803-05 CrossRef Medline

16. Ramagopalan SV, Dyment DA, Valdar W, et al; Canadian Collaborative Study Group. Autoimmune disease in families with multiple sclerosis: a population-based study. Lancet Neurol 2007;6:604-10 CrossRef Medline

17. Marrosu MG, Motzo C, Murru R, et al. The co-inheritance of type 1 diabetes and multiple sclerosis in Sardinia cannot be explained by genotype variation in the HLA region alone. Hum Mol Genet 2004; 13:2919-24 CrossRef Medline

18. Zorzon M, Zivadinov R, Nasuelli D, et al. Risk factors of multiple sclerosis: a case-control study. Neurol Sci 2003;24:242-47 CrossRef Medline

19. Daniels GH, Vladic A, Brinar V, et al. Alemtuzumab-related thyroid dysfunction in a phase 2 trial of patients with relapsing-remitting 
multiple sclerosis. J Clin Endocrinol Metab 2014;99:80-89 CrossRef Medline

20. Gold R, Montalban X. Multiple sclerosis: more pieces of the immunological puzzle. Lancet Neurol 2012;11:9-10 CrossRef Medline

21. Kozovska ME, Hong J, Zang YC, et al. Interferon beta induces Thelper 2 immune deviation in MS. Neurology 1999;53:1692-97 CrossRef Medline

22. Simpson CR, Anderson WJ, Helms PJ, et al. Coincidence of immunemediated diseases driven by Th1 and Th2 subsets suggests a common aetiology: a population-based study using computerized general practice data. Clin Exp Allergy 2002;32:37-42 CrossRef Medline

23. Edwards LJ, Constantinescu CS. A prospective study of conditions associated with multiple sclerosis in a cohort of 658 consecutive outpatients attending a multiple sclerosis clinic. Mult Scler 2004;10: 575-81 CrossRef Medline

24. Zivadinov R, Cox JL. Neuroimaging in multiple sclerosis. Int Rev Neurobiol 2007;79:449-74 CrossRef Medline

25. Weinstock-Guttman B, Zivadinov R, Horakova D, et al. Lipid profiles are associated with lesion formation over 24 months in interferon- $\beta$ treated patients following the first demyelinating event. J Neurol Neurosurg Psychiatry 2013;84:1186-91 CrossRef Medline

26. Zivadinov R, Weinstock-Guttman B, Hashmi $\mathrm{K}$, et al. Smoking is associated with increased lesion volumes and brain atrophy in multiple sclerosis. Neurology 2009;73:504-10 CrossRef Medline

27. Polman CH, Reingold SC, Edan G, et al. Diagnostic criteria for multiple sclerosis: 2005 revisions to the "McDonald Criteria." Ann Neurol 2005;58:840-46 CrossRef Medline

28. Weinstock-Guttman B, Jacobs LD, Brownscheidle CM, et al; New York State Multiple Sclerosis Consortium. Multiple sclerosis characteristics in African American patients in the New York State Multiple Sclerosis Consortium. Mult Scler 2003;9:293-98 CrossRef Medline

29. Zivadinov R, Rudick RA, De Masi R, et al. Effects of IV methylprednisolone on brain atrophy in relapsing-remitting MS. Neurology 2001;57:1239-47 CrossRef Medline
30. Smith SM, Zhang Y, Jenkinson M, et al. Accurate, robust, and automated longitudinal and cross-sectional brain change analysis. $\mathrm{Neu}$ roimage 2002;17:479-89 CrossRef Medline

31. Zivadinov R, Heininen-Brown M, Schirda CV, et al. Abnormal subcortical deep-gray matter susceptibility-weighted imaging filtered phase measurements in patients with multiple sclerosis: a case-control study. Neuroimage 2012;59:331-39 CrossRef Medline

32. Benjamini Y, Drai D, Elmer G, et al. Controlling the false discovery rate in behavior genetics research. Behav Brain Res 2001;125:279-84 CrossRef Medline

33. Fox RJ, Miller DH, Phillips JT, et al; CONFIRM Study Investigators. Placebo-controlled phase 3 study of oral BG-12 or glatiramer in multiple sclerosis. $N$ Engl J Med 2012;367:1087-97 CrossRef Medline

34. Ponsonby AL, Dwyer T, van der Mei I, et al. Asthma onset prior to multiple sclerosis and the contribution of sibling exposure in early life. Clin Exp Immunol 2006;146:463-70 CrossRef Medline

35. Makhlouf K, Weiner HL, and Khoury SJ. Potential of beta2-adrenoceptor agonists as add-on therapy for multiple sclerosis: focus on salbutamol (albuterol). CNS Drugs 2002;16:1-8 Medline

36. Vaidya B, Kendall-Taylor P, Pearce SH. The genetics of autoimmune thyroid disease. J Clin Endocrinol Metab 2002;87:5385-97 CrossRef Medline

37. Barkhof F, Calabresi PA, Miller DH, et al. Imaging outcomes for neuroprotection and repair in multiple sclerosis trials. Nat Rev Neurol 2009;5:256-66 CrossRef Medline

38. Buckle GJ. Functional magnetic resonance imaging and multiple sclerosis: the evidence for neuronal plasticity. J Neuroimaging 2005; 15:82S-93S CrossRef Medline

39. Pelletier J, Audoin B, Reuter F, et al. Plasticity in MS: from functional imaging to rehabilitation. Int MS J 2009;16:26-31 Medline

40. Strasser-Fuchs S, Enzinger C, Ropele S, et al. Clinically benign multiple sclerosis despite large $T 2$ lesion load: can we explain this paradox? Mult Scler 2008;14:205-11 Medline 